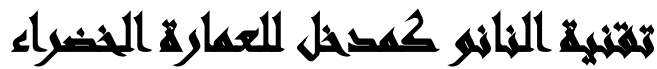

[0]

\author{
أحمد نبيه المنشاوى \\ قسم الهندة المعمارية، المعهذ التكنولوجى العالى بمدينة العاشر من رمضان
}

\section{المستخليك}

البحث يسلط الضوء على الإهتمام بتقنية النانو ومواد النانو المتعارف عليها في العمارة

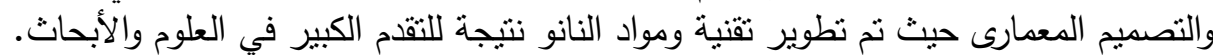

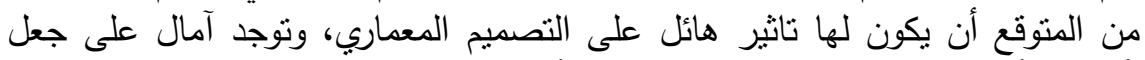

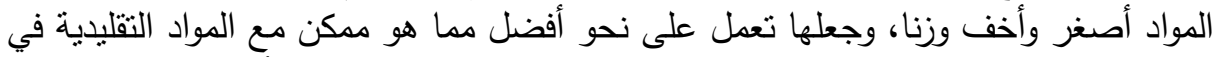
مجال الاستدامة وتوليد الطاقة، متل خلايا الوقود المعتمده على النانو أو الخلايا الضوئية النية، حيث أنها تستطيع أن تُقدم مزيدا من الكفاءة عما هو مناح مع المواد التقليدية.

\section{$x$}

يعرض البحث الروابط بين تقنية النانو - والعلوم والهندسة على المستوى الجزيئي والكيمياء والعمارة الخضراء، والتي تهدف إلى التقليل من الآثار البيئية من خلال الحفاظ على الموارد والقضاء على الهدر في مراحل البناء والإنتاج.

ويلخص البحث توصيات بثأن التدابير العامة للمساعدة في تحويل النطور من تقنية النانو إلى تقنية النانو الخضراء .وعند إدخال تقنية جديدة إلى مجال منل صناعة البناء والنتبيد، ينبغي للمرء دائما في المقام الأول دراسة الفوائد التي يمكن أن تحققها، ففي حالة تطبيق تقنية النانو نتحدث عن القيمة المضافة والوظائف الإضافية، وبهذه الطريقة يساهم في نطور كل من المواد النانوية وما ينجم عنها من منتجات النانو. عمارة النانو الخضراء هى عباره عن اندماج تقنية النانو الخضراء مع العمارة، حيث أدت المخاوف من تقنية النانو الى توخى الحذر من الأضرار الجانبية على الأنسان والبيئة ولذلك

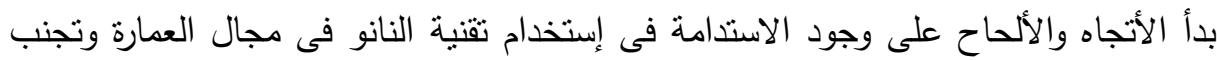

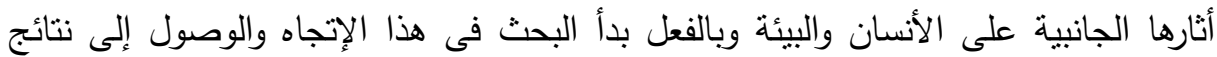

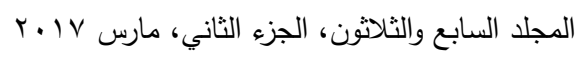


مُبشره لمستقبل أفضل لمجال العمارة وظهرت تلك النتائج فى التصميم حيث بدأ ظهور مدن

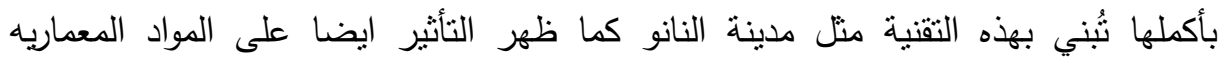

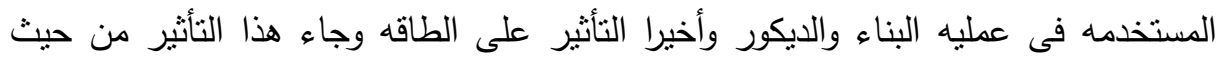

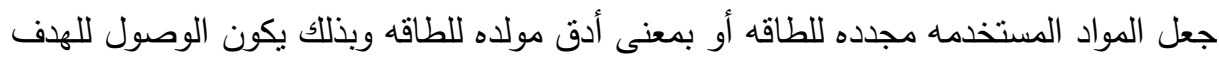
من تقنية النانو قد تحقق ولكنه تحقق مع وجود الاستدامه فى المبانى وبذلك نضمن مستقبل أفضل لمجال العمارة.

وبالتالي فإن إستخدام تقنية النانو ليست غاية في حد ذاتها ،ولكنها نتيجة للطلب المستمر

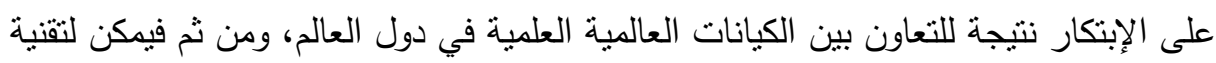

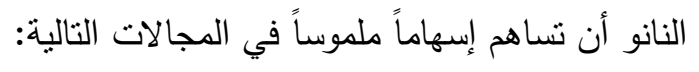
1. تعظيم الاستفادة من المنتجات الحالية r. الحد من الأضرار فى المواد الحالية. r. انخفاض في الوزن أو الحجم. ـ. تخفيض في عدد من مراحل الإنتاج. 0. زيادة كفاءة إستخدام المواد. 7. كفض الحاجة الى الصيانة في مرحلة التشغيل.

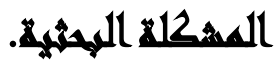

تواجه الهندسة المعمارية العديد من التحديات مثل التكنولوجيا، البيئة، الطاقة، الاستدامة، والإقتصاد، ومن التحديات السابقة سوف تركز الدراسة على التكنولوجيا متمثلكه في تقنية النانو وتأثيرها على العمارة من خلال المواد .والسؤال المطروح على الساحة الان، هو هل تستطيع

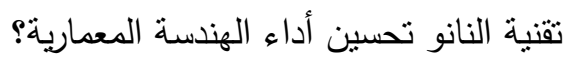




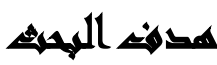

من خلال ما تقدم يُمكن تحديد هدف البحث في النقاط التالية: ا ـ تعريف مفهوم مواد النانو بالإستتاد إلى إستخدام تقنية النانو في المباني. r. تحسين أداء المبانى إستتاداً على تقنية النانو في المستقبل.

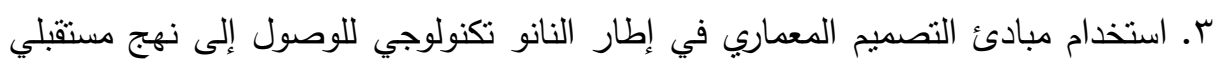
في مجال العمارة الخضراء.

\section{هزغية المبهشي}

بناءً علي إثكالية البحث والهدف منه، تم وضع فرضية البحث والتي يسعي البحث إلي هي

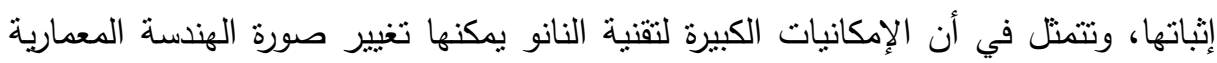
من خلال تطوير أداء المواد والخامات المستخدمه في البناء.

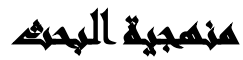

اعتمدت منهجية البحث علي النظامين الإستقرائي والتحليلي المقارن للوصول إلى دورة الحياة ( life cycle) في مراحل البناء بمساعدة تقنية النانو التي تؤدي إلى نهج مستقبلي في لإني مجال العمارة الخضراء. • أولا: مقدمة عامة للبحث تشمل على تعريف تقنية النانو وتطبيقاتها في المجالات المختلفة. • ثانيا: التركيز على المواد النانوية في البناء وتأثثرها على تحسين الطاقة والكفاءة والاستدامة. وهذا من شأنه إنشاء مواد جديدة مبتكرة تجعل هناك ثثرة في الهندسة المعمارية كومثال علي ذللك منزل نانو . • ثالثا: إستخدام المنهج المقارن بين منزل نانو وتطبيق ثقنية النانو على المباني القائمة حاليا، والذي بدورة يقودنا لتسليط الضوء على تقنية النانو الخضراء. • رابعا: تأثثر مخاطر تقنية النانو لإتخاذ الإحتياطات ضد الآثار الجانبية على الإنسان والبيئة، وبالتالي فإن أهمية هذا النهج هو الإصرار على الإسنمرار في توظيف التكنولوجيا

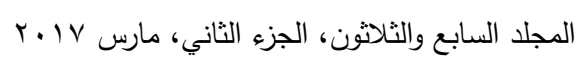


الحديثة في مجال الهندسة المعمارية وذلك لجعل نانو العمارة الخضراء ضمانا للإستفادة من تقنية النانو ولتجنب آثارها الجانبية على المجتمع والبيئة، مما أدى إلى نتائج واعدة من أجل مستقبل أفضل للهندسة المعمارية.

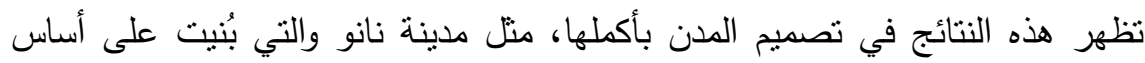
هذه التكنولوجيا والتي أثرت بدورها على مواد البناء والمواد المنتجة للطاقة، مما أدي إلي لهي

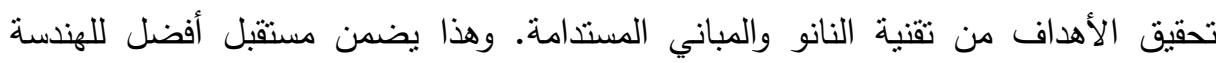

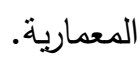
• وأخيرا: تحليل دورة الحياة ( life cycle) في مراحل البناء بمساعدة تقنية النانو التي تؤدي إلى نهج مسنقبلي في مجال العمارة الخضراء وتؤدى إلى إنخفاض في إستهلاك المواد الخام والطاقة والحد من إنبعاثات ثانى أكسيد الكربون وبالتالى الحد من التلوث والحفاظ

$$
\begin{aligned}
& \text { على الموارد الاقتصادية. } \\
& \text { 1-علم الناتو: } \\
& 1 \text { - } 1 \text { تعريف "علم النانو": }
\end{aligned}
$$

- المقصود بكلمة النانو هي بادئه مشتقه من كلمة Nanos الإغريقية التي تعني القزم وفي مجال العلوم يعني النانو جزء من المليار. - علم النانو ذللك العلم الذي يعتني بدراسة وتوصيف مواد النانو وتعيين خواصها وخصالها

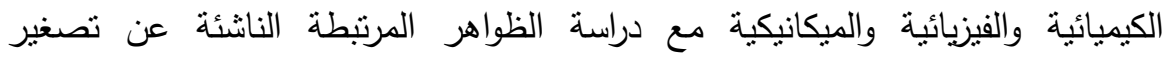

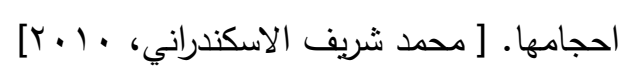

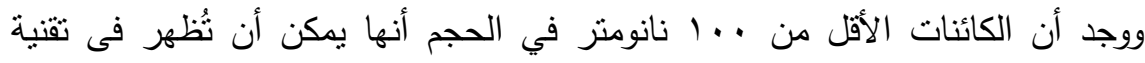

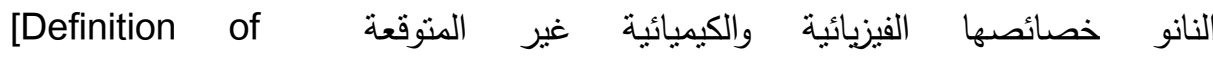
Nanoscience, 2008] 


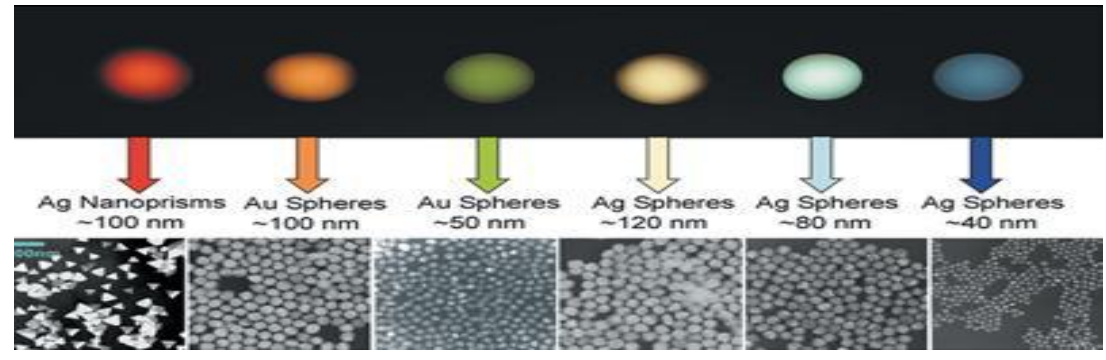

شكل(1):جزيئات الذهب والفضة لديهم الوان مختلفة بناءا على الثكل والحجم المصدر Northwestern University

تمثل قاعدة النانو تكنولوجى فى مسألتين:

الاولى: بناء المواد بدقة من لبنات صغيرة والحرص على مرحلة الصغر يؤدى إلى مادة خالية من الثوائب ومستوى أعلى جداً من الجودة والتشغيل. الثثانية: أن خصائص المواد قد تتغير بصورة هائلة عندما تتجزأ الى أصغر وأصغر ، وبن وبخاصة عند الوصول إلى مقياس النانو . ا r-r تاريخ تقنية النانو: شكل (r )

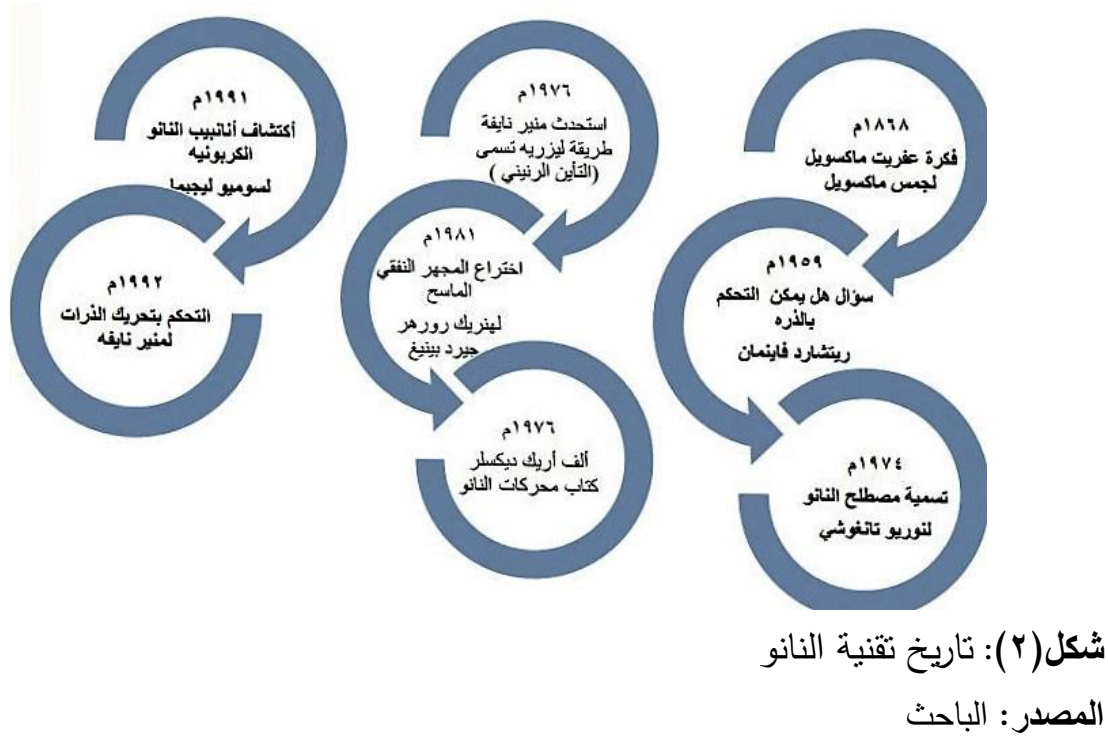


مجلة العلوم البيئية

معهد الدراسات والبحوث البيئية - جامعة عين شمس له

1- - - مبادئ ومميزات تقنية النانو: شكل(r) • ستكون المواد الناتجة أكثر دقة من تلك المصنوعة بطريقة تقليدية

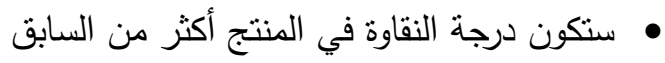
• توحيد نوعية المنتج • تقليل تكلفة الإنتاج وخفض الطاقة المستهلكة في التصنيع والتشغيل

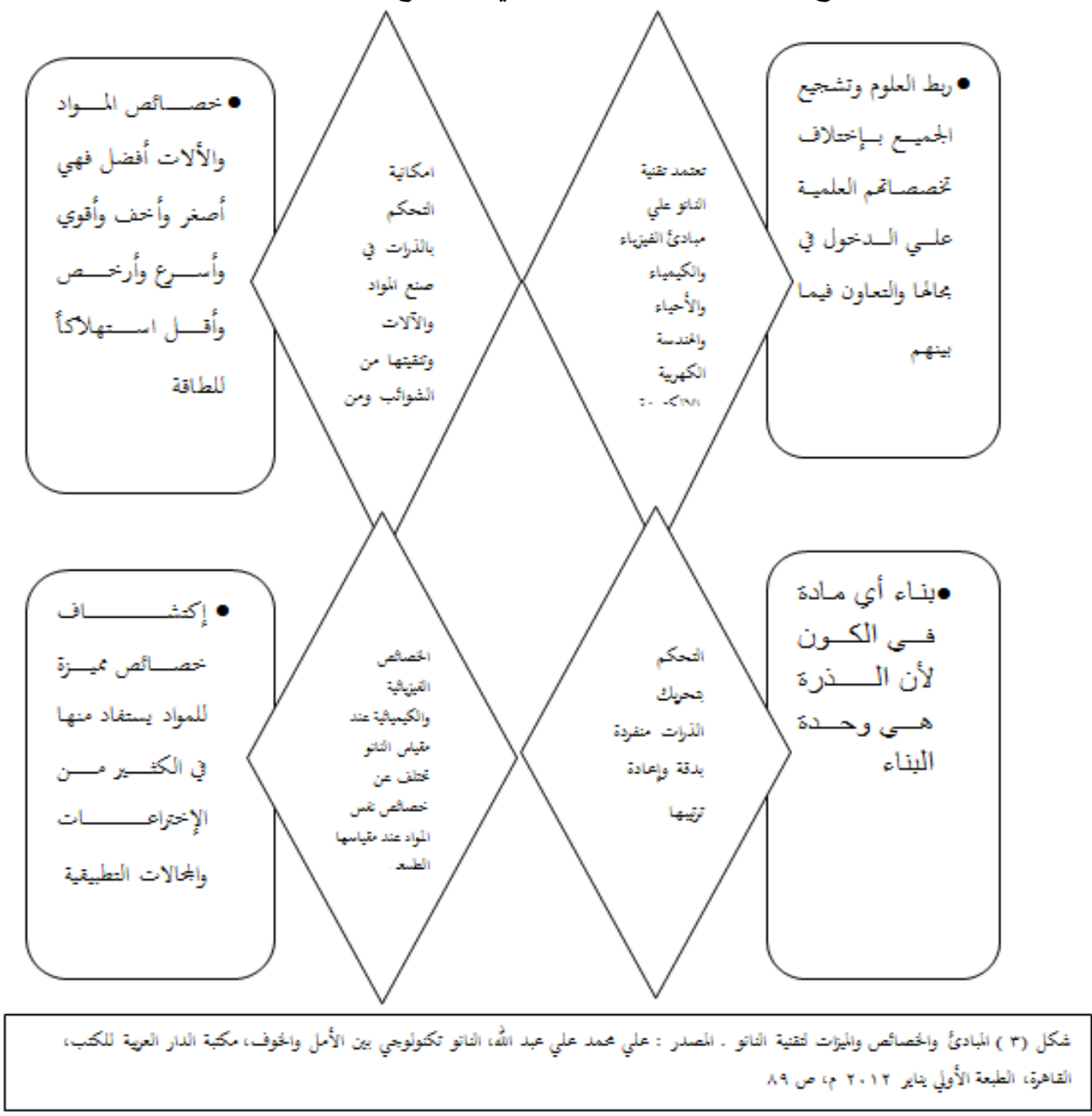




\section{r - عمارة النانو تكنولوجى:}

r-1 تعريف "عمارة النانو تكنولوجي: هي محاكاة العمارة في ظل ثورة النانو الجديدة في غضون القرن الـ آY. واستخدام تقنيه النانو في الهندسة المعمارية يختلف من المواد

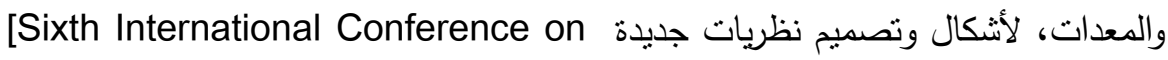
nanotechnology in construction , 2014] r-r - أهداف عمارة النانو تكنولوجي:

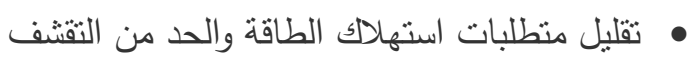

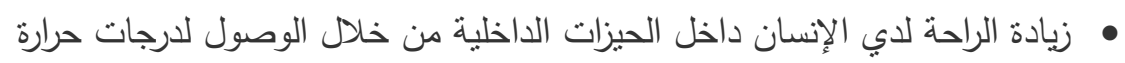

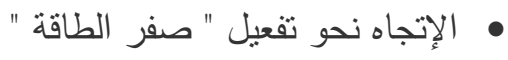

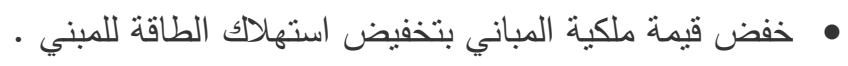

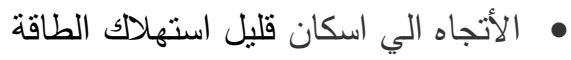
• المحافظة علي سلامة النظام البيئي من خلال التقليل من كمية انبعاثات غاز ثاني اكسيد

$$
\begin{aligned}
& \text { الكربون في البيئة . } \\
& \text { • الحصول علي مبني يتحكم في درجات الحرارة والرطوبة حسب الظروف المناخية }
\end{aligned}
$$

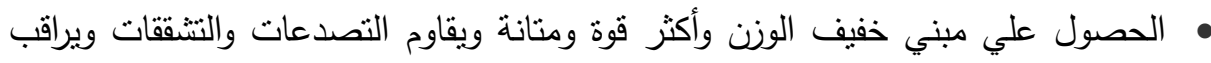

$$
\begin{aligned}
& \text { الأعطال والأضرار ويصلحها بنفسه . } \\
& \text { • الحصول علي مبني ينظف نفسه ذاتياً. }
\end{aligned}
$$

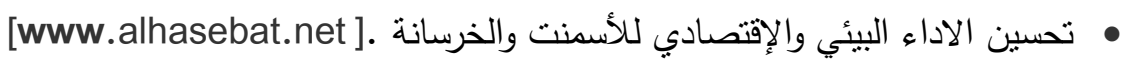

$$
\begin{aligned}
& \text { r-r مبادئ عمارة النانو تكنولوجي: } \\
& \text { فاعلية الموارد }
\end{aligned}
$$

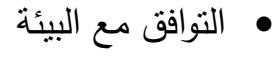

$$
\begin{aligned}
& \text { • فاعلية الطاقة } \\
& \text { الوقاية من التلوث }
\end{aligned}
$$


r- تطبيقات عمارة النانو: سوف تدخل تقنية النانو في إنتاج مواد البناء لتحسين خصائصها ووظائفها،منل المواد المستخدمة في الدهانات والمواد المضافة للخلطات الخراسانية مثل السيليكا ورمال السيليكا أو ثاني أكسيد السيليكون، والمواد الأسمنتية، والجبسية،والبلاط، والسيراميك، وتحسين صناعة الزجاج وصناعة الأخشاب وصناعة

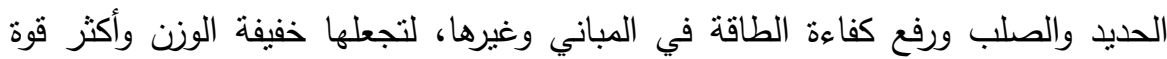
ومتانة ومقاومة للتصدعات والتشققات والتآكل، ولتقيد في حماية الأسطح والجدران من إلتصاق الغبار والملوثات، والمحافظة على ثبات درجات الألوان، والعزل الحراري، ومقاومة

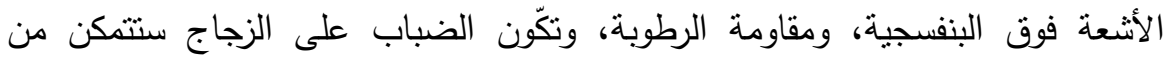
تتظيف الأسطح بصورة ذاتية وتلقائية، ومساعدة مواد البناء في التقليل من كمية إنبعاثات غاز ثاني أكسيد الكربون في البيئة، وبالتالي المحافظة على سلامة النظام البيئي

[Nanotechnology Applications,2009] r-1 الانشـــاء: يمكن لتقنية النانو زيادة معدل الإنشاءات عن طريق سرعة التشييد وبسعر

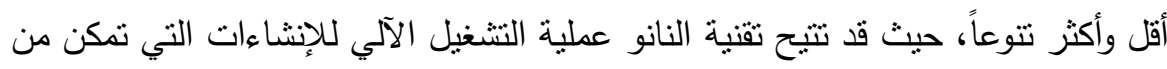

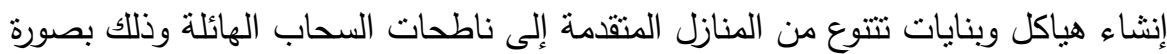

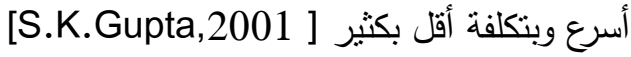
r-r الطاقــة : تتمنل في أكثر المشروعات تقدما والمرتبطة بمجال الطاقة في مراحل التخزين، التحويل وتحسينات التصنيع، بالإقلال من المواد المستخدمة ومعدلات العملية التصنيعية، وتوفير الطاقة من خلال طرق أفضل للعزل الحراري، وكذللك توفير مصادر لئرل

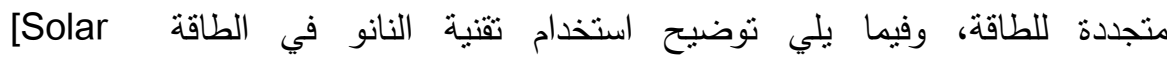

تقليص استهلاك الطاقة: من خلال تطبيق أفضل أساليب العزل، عن طريق إستخدام الإضاءة الكافية وأساليب الإحترار بإستخدام مواد أقوى في الإضاءة لنستخدم في قطاعات التتييد ونحوه وتنتهلك اللمبات الضوئية المستخدمة حاليا ه\% فقط من الطاقة الكهربائية. 
أ- زيادة كفاءة إنتاج الطاقة: تقنية النانو قد تساعد على زيادة كفاءة تحول الضوء من خلال

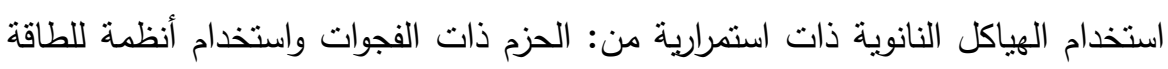
أكثر صداقة للبيئة عن طريق استخدام خلية وقود نتنعل بواسطة الهيدروجين، والتي تتتج

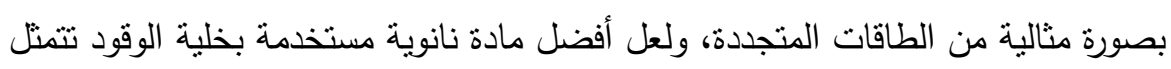

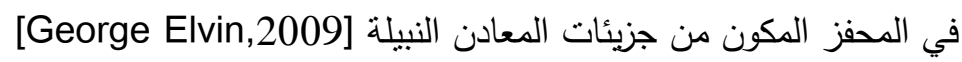
r-ب الخامـات:

أ- المطاط المعدني: هو مادة مرنة كالمطاط وناقلة ومتينة كالمعدن تم ترتيب جزيئاتها بتقنية

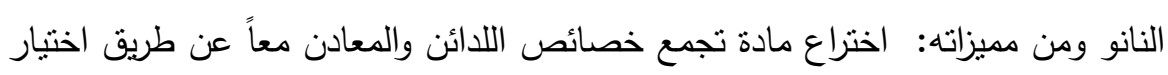

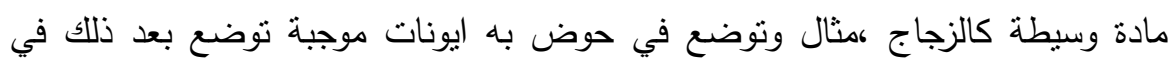

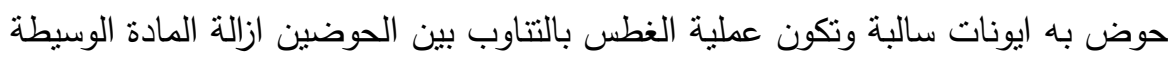

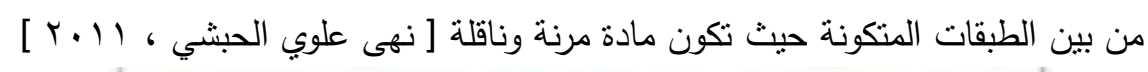
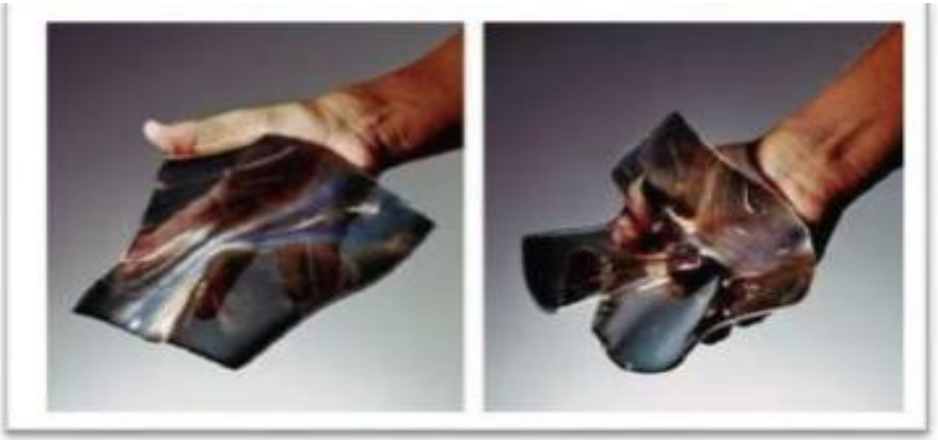

شكل(؟) ): المطاط المعدني ذو مرونة عالية

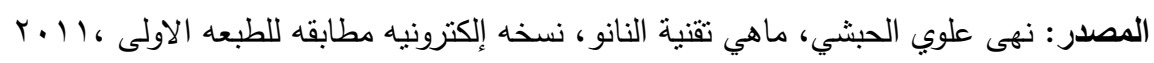

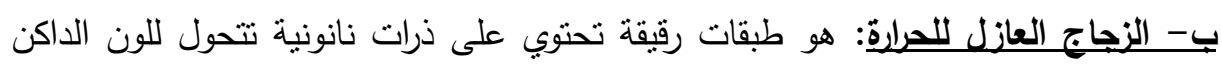

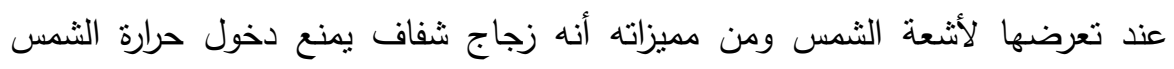
وبالتالي نوفير الكهرباء لتبريد المباني عن طريق تسليط تبار كهربائي على مواد نانونية داخل الزجاج وكلما زادت شدة التيار زاد تعتيم الزجاج. 


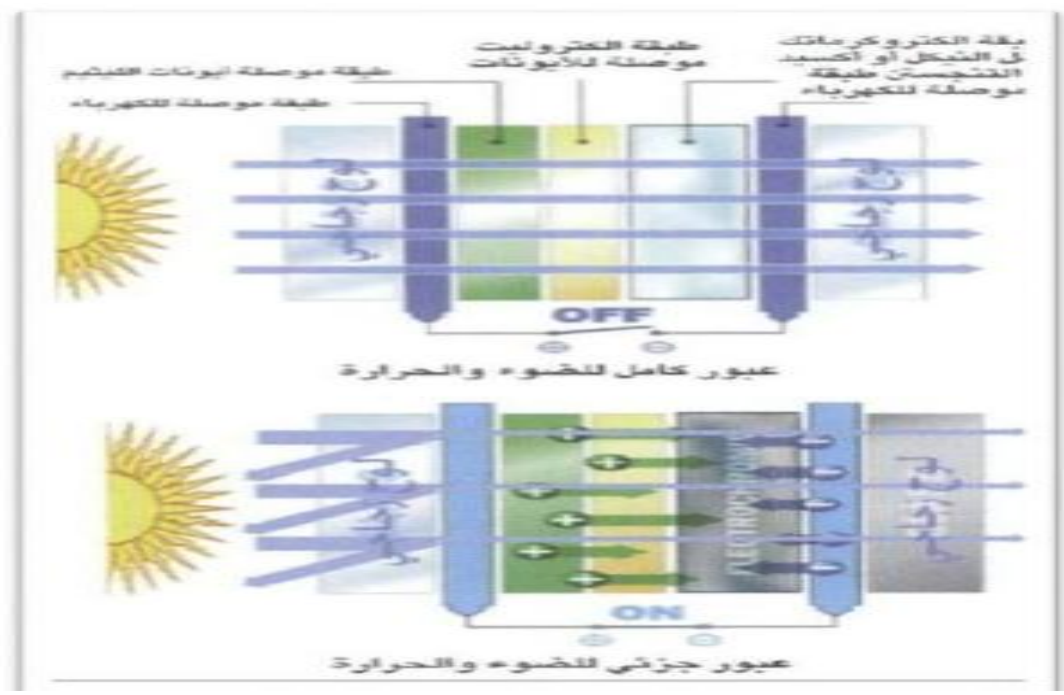

شكل(ه): فكرة عمل الزجاج العازل للحرارة

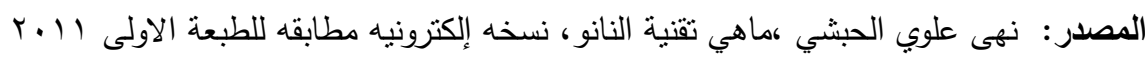
تتبدل خواص الإمنصاص والإنعكاس للضوء لهذه المواد النانونية فيحدث تفاعل كهرو كيميائي ينتج عنه اللون القاتم ويستخدم في الأسطح الزجاجية لعزل المباني والأماكن

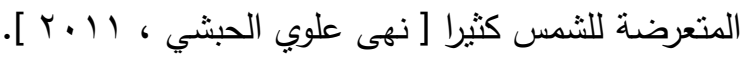
ع-أضرار تقنية النانو: أظهرت دراسة جامعة اكسفورد أن نانو جزيئات ثاني أكسيد التيتانيوم المضادة للشمس أصابت الحمض النووي DNA للجلد بالضرر، حيث أظهرت

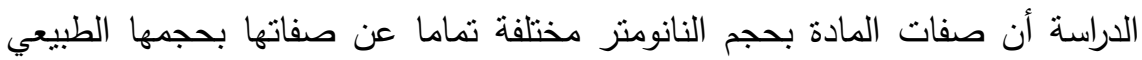

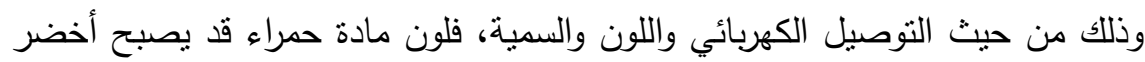
عندما نأخذها بحجمها الصغير والكربون في مادة الجرافايت طيّع لكنه أقوى من الفولاذ

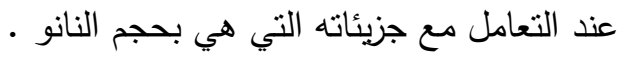
وتوضح الدراسة أن استعمالات هذه التقنية قد بدأت تتسرب إلى حقل المواد الغذائية والقطاع الزراعي من دون معرفة المستهلكين وأظهرت تجربة جديدة من جامعة روتشيستر 
أجريت على فئران تتفست جزيئات النانو وتنين فيما بعد أنها أستقرت في الدماغ والرئتين ما أدى إلى مضاعفات صحية خطيرة.

ه- العمارة الخضراء: تعتبر العمارة الخضراء أو المباني والمدن الصديقة للبيئة ،أحد الاتجاهات الحديثة في الفكر المعماري والذي يهتم بالعلاقة بين المباني والبيئة، وهناك

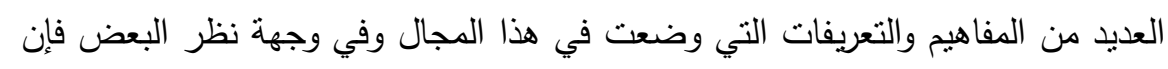
العمارة الخضراء هي منظومة عالية الكفاءة نتوافق مع محيطها الحيوي بأقل أضرار

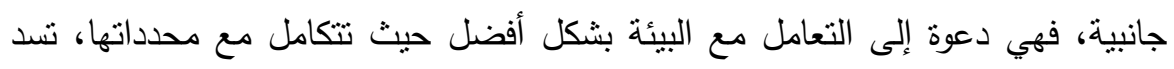

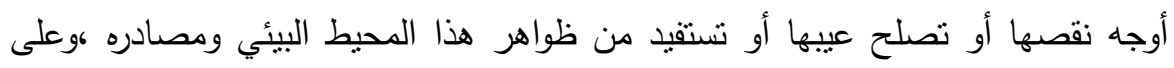

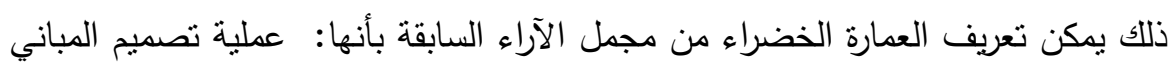
بأسلوب يحترم البيئة مع الأخذ في الاعتبار تقليل إستهلاك الطاقة والموارد مع تقليل تأثثرات الإنشاء والإستعمال على البيئة مع تعظيم الإنسجام مع الطبيعة. ه- - إنعايير ومبادئ العمارة الخضراء.

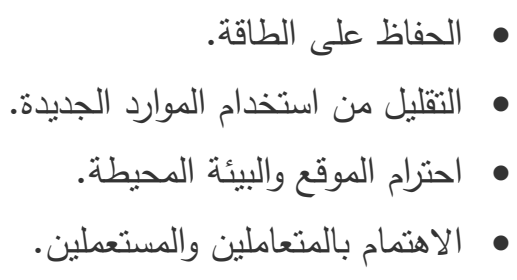

• • • • • ه-r تقنية النانو الخضراء: تقنية النانو الخضراء تتبر إلى إستخدام تقنية النانو لتعزيز

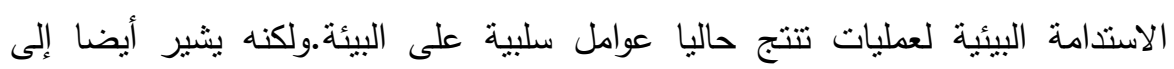
إستخدام منتجات تقنية النانو لتعزيز الاستدامة.

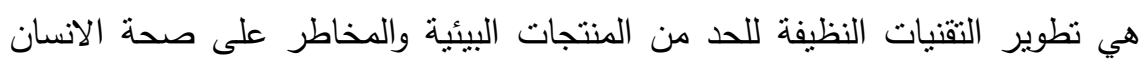

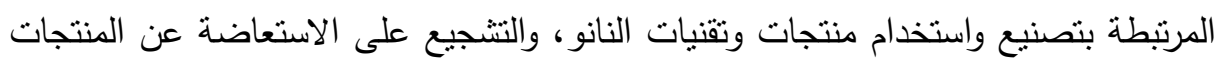

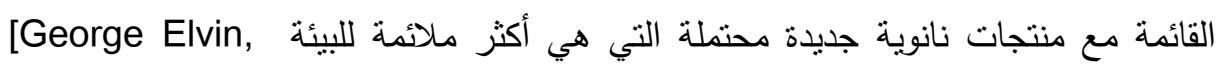


צ- مقارنة بين القدرة على تطبيق تقنية النانو في المباني القائمة ومنزل النانو

צ-1 تطبيق تقتية النانو على المباني القائمة: تطبيق المواد النانوية على المواد القائمة أتحسينها وجعلها أكثر منانة.

أ- التظظف الذاتي: تأثير اللوتس: في مشروع متحف آرا باسيس بإيطاليا ( روما ) شكل (7)، تم استخدام طلاء من مواد نانونيه تمكن من التنظيف بصورة ذاتية.

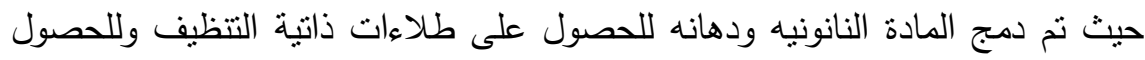
على سطح مقاوم لعوامل التعرية الخارجية، وقد تم دمجها في الأسطح البيضاء لضمان منانه منانه اللون، في مدينة ذات تلوث شديد [Nano Materials in architecture 2008].

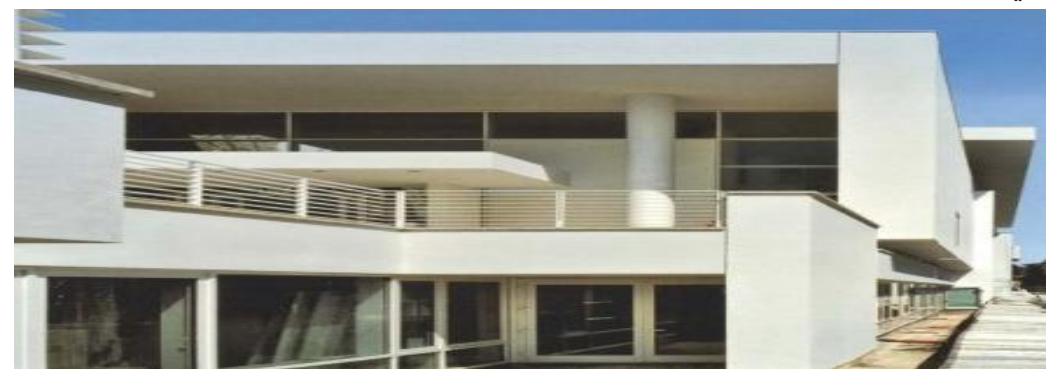

شكل(†): متحف آرا باسيس بايطاليا (روما)

المصدر: Interior architecture and Design.،Nano Materials in architecture ب- التظظف الذاتي ضوئي (Hydrophobic surfaces): في مشروع مطار ناريتا الدولي اليابان (طوكيو ) شكل (V)، هو مطار دولي يبعد عن العاصمة اليابانية طوكيو حوالي 70 كم في الاتجاه الثمالي الثرقي.

يعد مطار نارينا المطار الرئيسي الذي يخدم العاصمة تم استخدام الأسطح الطاردة للماء

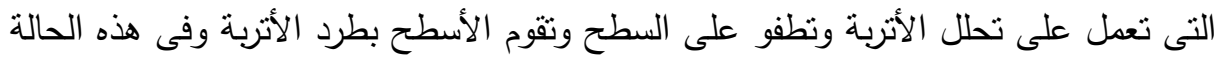

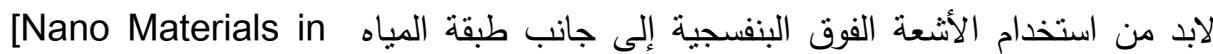
architecture ,2008] 


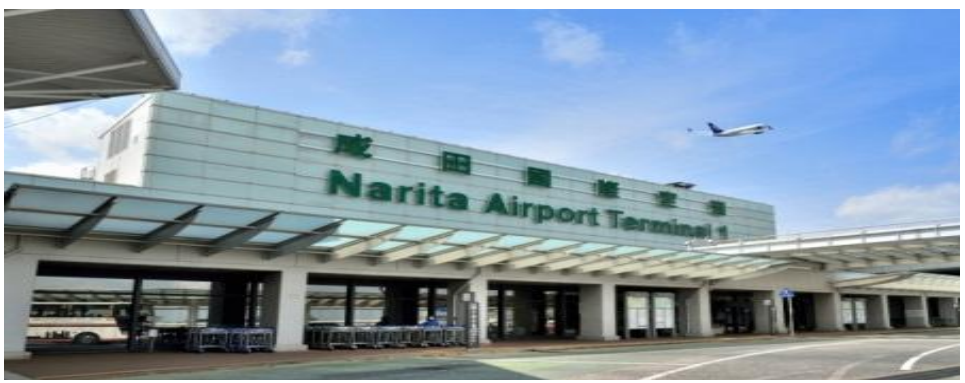

شكل(V): مطار ناريتا الدولي اليابان (طوكيو) www.passengerterminaltoday.com المصدر

ج- تنقبه الهواء Air-purifying: في كنيسه جبيل Richard Jubilee Church: بإيطاليا ( روما ) شكل (^)، نم استخدام تقنية النانو فى تتقية الهواء وتتقية الهواء من

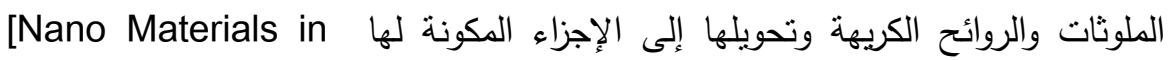
architecture ,2008]

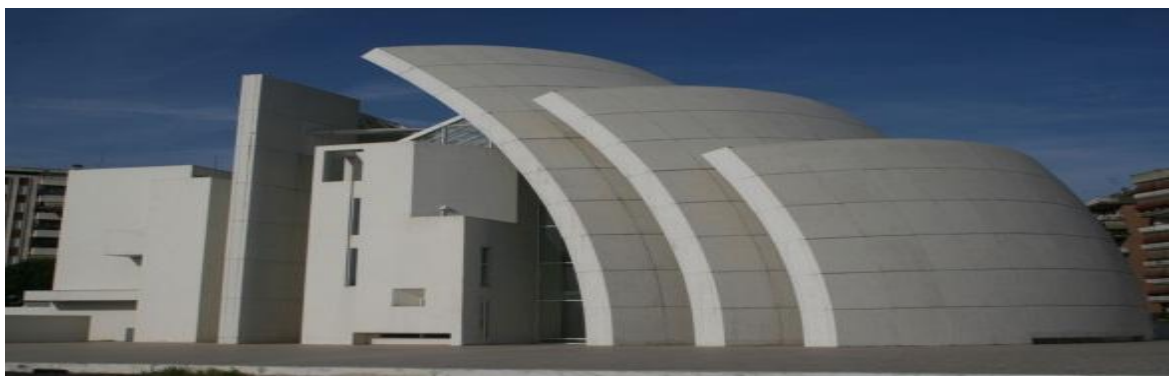

شكل(^): كنيسة جبيل (روما) Interior architecture and Design.، Nano Materials in architecture المصدر د- العزل Insulation Vacuum Solution (VIP): تم استخدام تقنية النانو لمبنى كeitzstraße

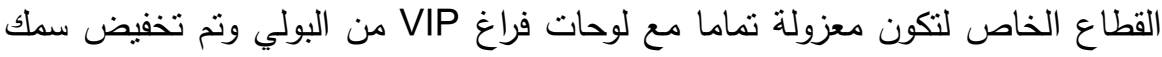

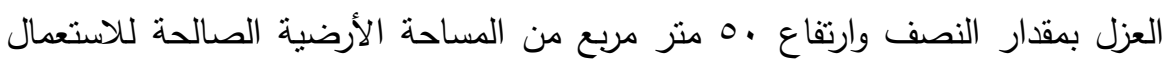

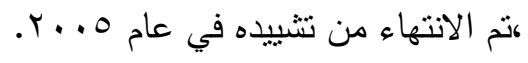




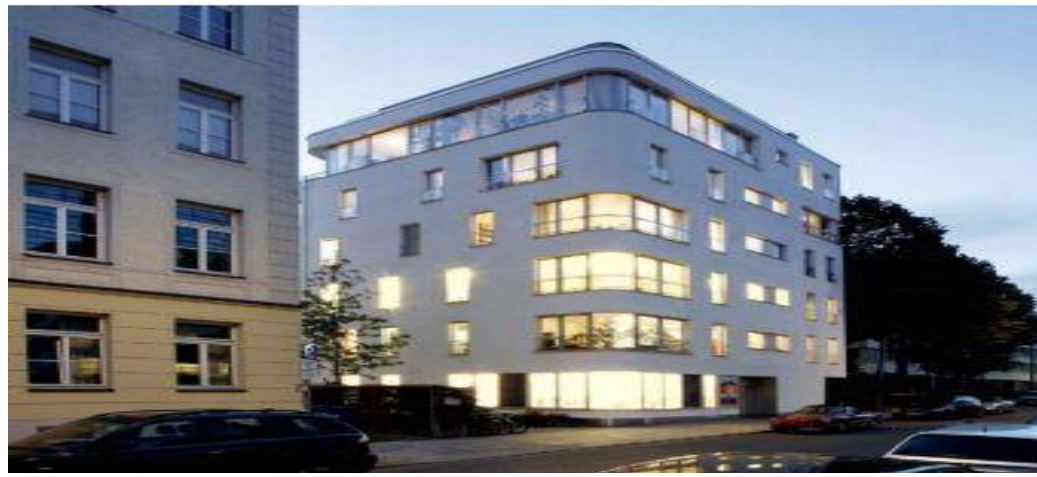

شكل(9): لمبنى Seitzstraße، بالمانيا ميونخ

المصدر http://www.academia.edu/1018084/NanoArchitecture-Nanotechnology and Architecture.

צ-r تطبيق تقتية النانو على منزل النانو: تم استعراض لنظام لابتكار منزل النانو في يناير 1 . . r شكل (• (1)، من قبل حكومة استراليا ومنسقة من قبل لجنة الخبراء. وكان الغرض منها نظوير وتقديم ورقة بحثية عن عمارة النانو الخضراء ودراسة لنظام الإبتكار

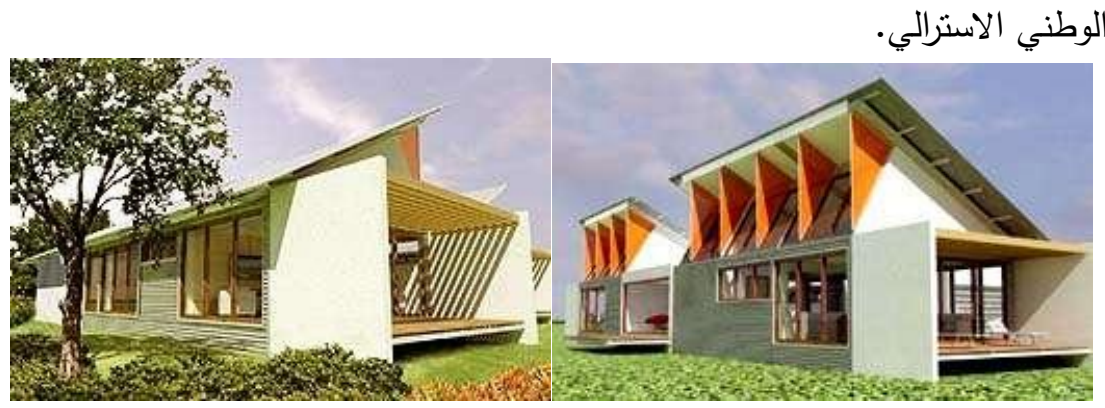

$$
\text { شكل( • 1): لقطات منظوريه منزل النانو }
$$

Venturos Australia building strength in innovation المصدر منرل • تم استخدام طلاء خارجي لمنزل النانو لديه خاصية التبريد الإشعاعي على السطح

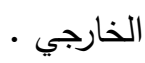

• تم استخدام سقف معدني مغلف بغطاء التبريد من جسيمات النانو بخاصية التبريد التى لا

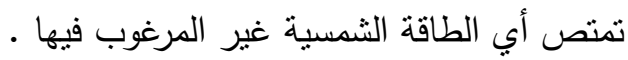


• تم إستخدام الأشعة فوق البنفسية / الأشعة تحت الحمراء تتقى وتعكس زجاج النوافذ من

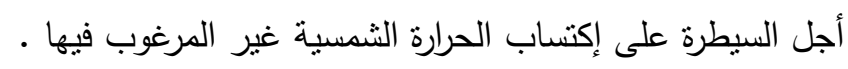
• • تم إستخدام زجاج التظظيف الذاتي المغلفة بالتيتانيوم.

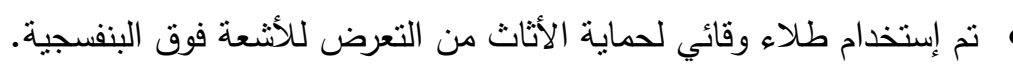
تم إستخدام أنظمة التحكم في نوعية المياه التي تعمل على إزالة الملونات من المياه، وتتقية المياه المتدفقة.

نم استخدام الدهانات المضيئة الملونة وصبغات للدهانات التي لا تحتفظ بالحرارة

[Nanotechnology Applications, 2009]

- مدخل لعمارة النانو تكنولوجى الخضراء: مدخل عمارة النانو تكنولوجي الخضراء يظهر تقييم المبنى باستخدام مراحل دورة الحياة للمبني، باستخدام المواد النانوية.

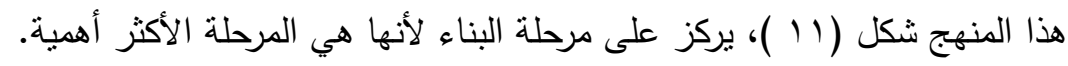

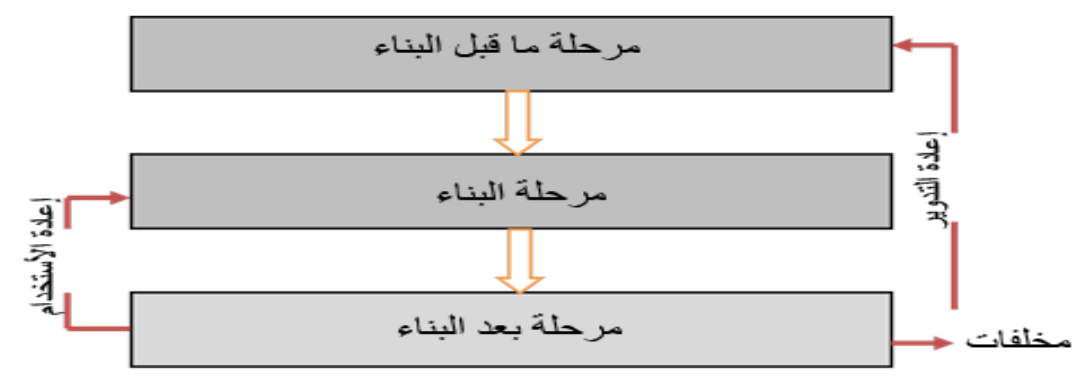

شكل( 11 ) : المراحل الثناث للمنهج وفقاً لدورة الحياة

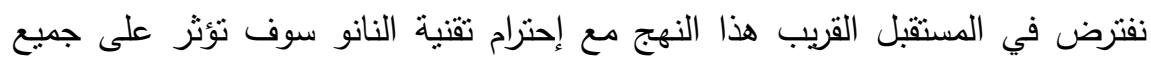

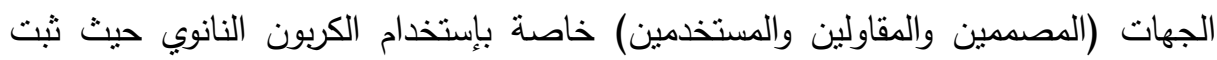
فعليتها في مجال الهندسة المعمارية وذلك بإضافة كمية صغيرة من الكربون النانوي في معظم المواد المستخدمة في البناء (الخرسانة والصلب، والبوليمرات والزجاج والطلاء .... الخ.). وتحسين خصائصها وجعل المبانى صديقة للبيئة. 


\section{- 1 - نتائج التحليل المقارن:}

1-تقنية النانو لديها القدرة على أن تصبح الرائدة في طرق البناء للألفية الجديدة والطراز المعماري في الدول المتقدمة وكذلك في العالم النامي. وتقنية النانو بالتأكيد ليست محل كل التقنيات الأخرى المستخدمة في الهندسة المعمارية، تقنية النانو هي عبارة عن تقنية جديدة من الممكن أن تقتح عالما جديدا من المواد والخامات الجديدة في البناء. r-ثقنية النانو تحسن الأداء المعماري (Improve Architecture Performance) وأيضا بالمساهمه على التغلب علي القضايا البيئية، منل ظاهرة الإحتباس الحراري. عن طريق تقليل إنبعاث غاز ثاني أكسيد الكربون CO2 بإستخام المواد النانونيه. على المرءء أن بيتبأ بأن هذه تقنية الجديدة الرائعة سيكون من الضروري إستخدامها في هذا القرن اب وعلينا أن نقوم بإستخدامها في الإتجاه الصحيح، للمساهمة في التتمية البشرية. ب-تقنية النانو تعطى للمواد خواص جديدة نساعدها على الصمود أمام الظروف المناخية المختلفة وبالتالى تعمل على خفض تكاليف التشغيل والصيانة وأيضا تكاليف الطاقة. ع-بإستخدام مبادئ دورة الحباة للمباني مع إحترام تقنية النانو يمكن الوصول إلى تقنية النانو

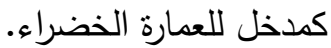
ه- نشر وتتجيع إستخدام التقنية النانويه الجديدة عن طريق إلقاء الضوء على النطبيقات

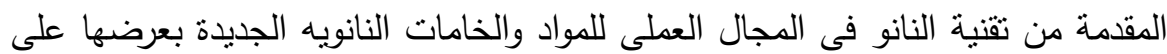
المهندسين المعماريين ومصمي الديكور الداخلي والمصممين للاراسة والإختبار . צ-عن طريق تقنية النانو في العمارة نم إنتاج دهانات ومواد طلاء جديدة مقاومة لأشعة

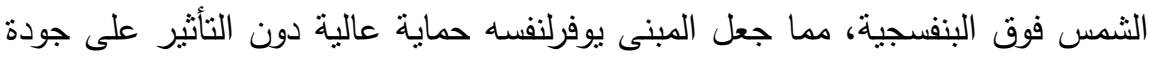
المنتج والعمر الإفتراضى للاهان.. كما تم تحسين الهواء ودرجة الحرارة الداخلية لأن

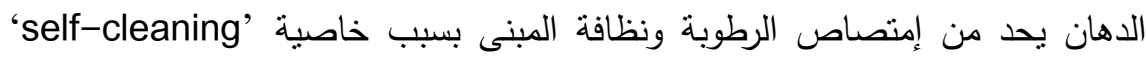
.وأيضا قلة التكلفة في طاقة المستخدمة للتكييف والتدفئة والصيانة المستمرة. 
V- التقدم في تقنية النانو تتطلب العديد من الأسئلة بين فئات المجتمع،

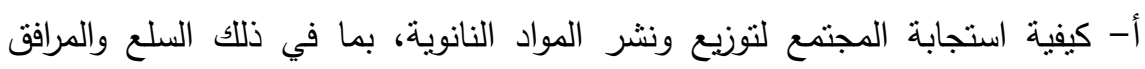
والخدمات وكيف سيكون هؤلاء شأن فى تغيير المجتمع؟ ب- كيفية إستخدام المهندس هذه التقنية المنطورة لخلق المساهمة فى الأفكار المبتكرة التي تتعكس إيجابا وتكون مفاهيم معمارية جديدة.

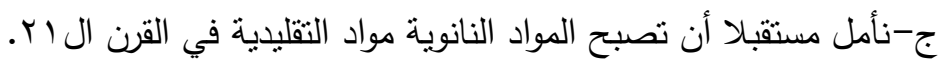

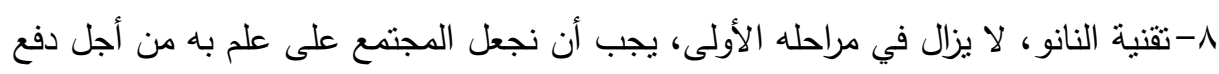

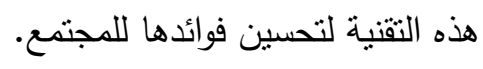
9-من المنظور الإنشائى والإقتصادى فتحقق عمارة النانو تكتولوجى مع إحترام لمبادئ العمارة

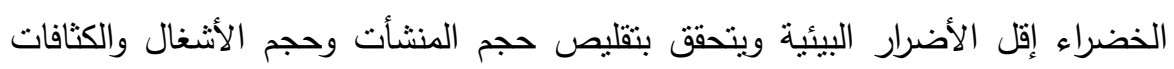
وتقليل الفاقد فى المواد المستخدمة والتكلفة.

\section{اللزوكياني}

1-على الحكومة تشجيع تصنيع المواد النانوية والمنتجات الخضراء للبناء مثل طلاء النانو،

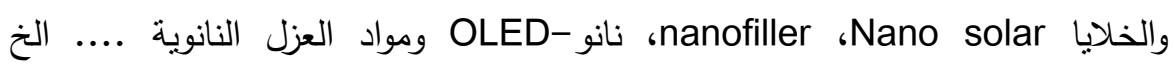
وإتاحتها للمستهلكين والمهندسين المعماريين، ولذلك ينبغي إنخفاض تكاليفها وأن تصبح متاحة في الأسواق مع مراعاة استدامة المنتجات .

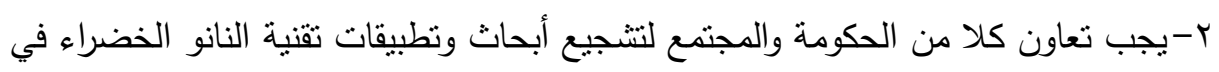
العديد من المجالات وتتجيع إندماجها في الهندسة المعمارية.

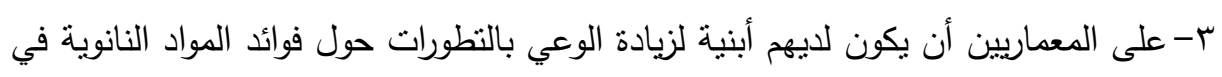

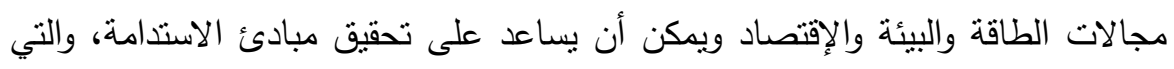

$$
\text { تشاعد على إنقاذ كوكبنا. }
$$

ع - لا بد أن يتم فرض مطالب من قبل ملاك المباني العامة والخاصة بإستخدام مواد صديقة للبيئة بشكل متزايد وفرض لوائح وقوانين في كثثر من الحالات. وهذه القوانين تجبر بولئ 
المهندسين بإستخدام المواد الصديقة للبيئة في المباني. وهذا يؤدي إلى طفرة في الطلب على تقنية النانو لبناء عمارة خضراء. ه-محاولة مواكبة التقدم التكنولوجي، وذللك بالتوعية بتقنية النانو وأهميتها عن طريق الندوات

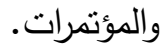
צ- إثارة البحث العلمي الخاص بتقنية النانو في العمارة وتطويره. V-تحقيق تقنية النانو الخضراء في مجال العمارة لتحقيق الاستدامة. 1-توظيف الخامات المنتجة في مجلات الحياة.

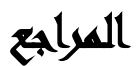

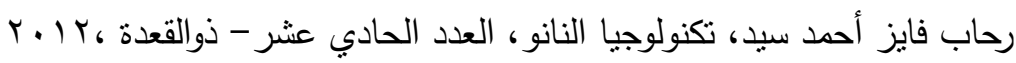

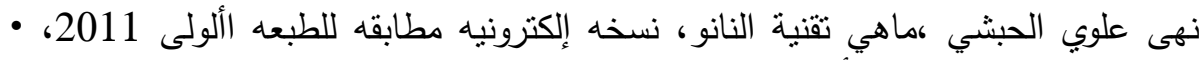

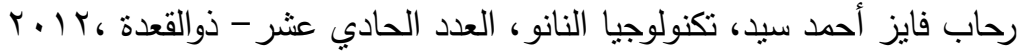

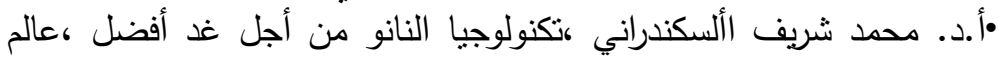

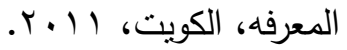

محمد شريف الاسكندراني ،كتاب تكنولوجيا النانو من أجل غد أفضل، سلسلة عالم المعرفة،

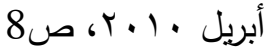

Leydecker, (2008): Nano Materials in architecture، Interior architecture and Design, Sylvia.

Satyendra rastogi "Mitra",(2001): Engineering Phisics , Vol-2 Written by S.K.Gupta Edited by Dr. Madhu Bala. Published by: in. Www.krishnaprakashan.com

Luisa filipponi and Duncan Stherland, Nano material science. Nanotechnology: A Brief Introduction، Interdisciplinary Nanoscience center (INANO) University of Aarhus، Denmark

Dr. George Elvin , (2009): Nanotechnology for Green Building

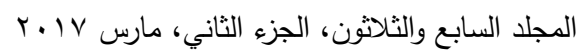


أحمد نبيه المنشاوى

Definition

of

Nanoscience:

Http://www.discovernano.northwestern.edu/whatis/index_ht ml/sizematters_html Retrieved December، 2008.

Nano living system http://www.nanolivingsystem.com/، Retrieved May، 2014.

Nanotechnology Applications. Http://understandingnano.com/ .Retrieved August،2009.

Light Tree. Http://www.evolo.us/architecture/light-tree-a-very-greensolution-topedestrian-lighting/\#more-3336 ‘Retrieved June، 2014.

Solar Energy. Http://www.nanosolar.com/technology/technologyplatform $: 2010$

NCCO. Http://www.rht.com.hk/ncco.php، Retrieved April، 2011.

Nanoarchitecture http://www2.arch.uiuc.edu/elvin/nanotech.htm ‘2010

Off the Grid. Sustainable Habitat 2020 http://www.yatzer.com/1095_off_the_gridsustainable_habit at_2020،2010

Http//www.alhasebat.net/vb/showthread.php?T=9801

Nanotechnology and Developing Countries Part 2: What Realities? Http://www.Azonano.com/details.asp?Articleid=1429 Retrieved August، 2009.

Sixth International Conference on nanotechnology in construction، 2014

Principles of Green Engineering. Green Nanotechnology: It's Easier Than You Think - Project on Emerging Technologies، USA. Retrieved February، 2009.

Nanotechnology Cairo university course، On January 2013

Mast Team، Materials science and technology (nanomaterials for architecture)

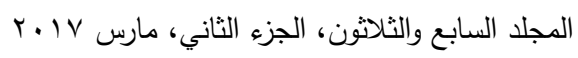


مجلة العلوم البيئية

معهد الدراسات والبحوث البيئية - جامعة عين شمس لهن

\title{
NANOTECHNOLOGY AS AN APPROACH TO
}

GREEN ARCHITECTURE

\author{
EL Menshawy, A. N. \\ Department of Architecture, HTI Tenth of Ramadan City
}

\begin{abstract}
The research highlights an extraordinary amount of interest in nanotechnologies and nanomaterials، terms now familiar not only to scientists، engineers، architects، and product designers but also to the general public. Nanomaterials and nanotechnologies have been developed as a consequence of truly significant recent advances in the material science community. Their use، in turn' is expected to have enormous consequences on the design and engineering of everything. Hopes exist for being able to make things smaller، lighter، or work better than is possible with conventional materials. In the sustainability and energy generation domain، for example، nano-based fuel cells or photovoltaics can potentially offer greater efficiencies than are possible with conventional materials.
\end{abstract}

